Marquette University

e-Publications@Marquette

School of Dentistry Faculty Research and

Publications

Dentistry, School of

9-1-2015

\title{
Color-to-Grayscale Conversion Using a Smart Phone Camera for Value Comparison
}

Seok-Hwan Cho

Marquette University, seokhwan.cho@marquette.edu

Accepted version. The Journal of Prosthetic Dentistry, Vol. 114, No. 3 (September 2015): 462-463.

DOI. (C) 2015 Editorial Council for the Journal of Prosthetic Dentistry. Published by Mosby, Inc. Used with permission. 


\section{Effect of Toothbrushing On Shade and Surface Roughness of Extrinsically Stained Pressable Ceramics}

Lessly A. Garza

Resident, Graduate Prosthodontics, Marquette University School of Dentistry

Milwaukee, WI

Geoffrey Thompson

Assistant Professor and Program Director, Postgraduate Program

in Prosthodontics, Marquette University School of Dentistry

Milwaukee, WI

Seok-Hwan Cho

Assistant Professor and Director, Predoctoral Prosthodontics and Biomaterials, Department of General Dental Sciences, Marquette University School of Dentistry

Milwaukee, WI

David W. Berzins

Associate Professor and Director, Department of General Dental Sciences, Graduate Dental Biomaterials, Marquette University

School of Dentistry

Milwaukee, WI

The Journal of Prosthetic Dentistry, Vol. 115, No. 4 (April 2016): pg. 489-494. DOI. This article is (C) Elsevier and permission has been granted for this version to appear in e-Publications@Marquette. Elsevier does not grant permission for this article to be further copied/distributed or hosted elsewhere without the express permission from Elsevier. 
NOT THE PUBLISHED VERSION; this is the author's final, peer-reviewed manuscript. The published version may be accessed by following the link in the citation at the bottom of the page.

\section{Abstract}

\section{Statement of problem}

The effect of toothbrushing on extrinsically stained pressable ceramic materials is unknown.

\section{Purpose}

The purpose of this in vitro study was to investigate the effects of toothbrushing on the shade and surface roughness of extrinsically stained, pressable ceramics.

\section{Material and methods}

Two materials, leucite-based (IPS Empress Esthetic [EE]; Ivoclar Vivadent AG) and lithium disilicate-based ceramic (IPS e.max Press [EP]; Ivoclar Vivadent AG), were studied. For each material, 24 disk-shaped specimens, $10 \mathrm{~mm}$ (diameter) $\times 3 \mathrm{~mm}$ (height) were fabricated. Three different methods $(n=8)$ of applying extrinsic stains were performed on each material: glazed only (G, control group); stained then glazed (SG); and stained and glazed together $(T)$. The specimens were brushed with a multistation brushing machine under a load of $1.96 \mathrm{~N}$ at a rate of 90 strokes per minute with a soft and straight toothbrush (Oral-B \#35) and a 1:1 toothpaste and distilled water slurry. Shade and roughness were measured at baseline and at $72,144,216$, and 288 hours, which is equivalent to 3, 6, 9, and 12 years of simulated toothbrushing for 2 minutes twice a day. A repeated measures ANOVA with staining technique as a fixed factor was used to evaluate shade and roughness $(a=.05)$.

\section{Results}

For EE groups, no significant change was found after 12 years of simulated toothbrushing regarding shade and surface roughness, irrespective of staining techniques $(P>.05)$. However, EP groups demonstrated a significant shade change and an increase in surface roughness after 12 years of simulated toothbrushing. Shade change was found to depend on the method of applying stain. For the EP-SG technique, a significant shade change was observed only at the 9 - to 12 -year interval $(P=.047)$. However, the EP-T technique demonstrated a significant difference in shade between baseline and 3 years $(P=.005)$ and in the 6- to 9-year interval $(P=.005)$. Surface roughness was only significantly affected at baseline and 3 years for the EP-T group $(P=.005)$.

\section{Conclusions}

For the shade and surface roughness of the EE groups, no statistically significant difference was found after 12 years of toothbrushing, irrespective of the staining technique. The shade and surface roughness of the EP groups were significantly statistically affected by toothbrushing time; only shade changes were found to depend on technique.

Clinical Implications

Even though a statistically significant change was found, 12 years of toothbrushing did not produce a clinically relevant shade change or increase in the surface roughness of extrinsically stained and/or glazed IPS Empress Esthetic and IPS e.max Press pressable ceramics.

The Journal of Prosthetic Dentistry, Vol. 115, No. 4 (April 2016): pg. 489-494. DOI. This article is @ Elsevier and permission has been granted for this version to appear in e-Publications@Marquette. Elsevier does not grant permission for this article to be further copied/distributed or hosted elsewhere without the express permission from Elsevier. 
NOT THE PUBLISHED VERSION; this is the author's final, peer-reviewed manuscript. The published version may be accessed by following the link in the citation at the bottom of the page.

The ability to recreate a natural appearance in ceramic restorations is essential for clinical success; $\underline{1}$ and $\underline{2}$ fortunately, this is now easier because of the improvements in restorative materials. $\underline{3}$ Improved shade selection and translucency in ceramic materials have led to an increased use of monolithic ceramic restorations. ${ }^{4}$ Because esthetic veneering is not done for monolithic materials, custom shade matching with surface color correction pigments may be required to adjust the shades of ceramic restorations. This process is known as extrinsic staining, $\underline{5}$ and $\underline{6}$ which can be described as the superficial application of stains to the outermost layers of ceramic restorations. Stains are conventionally applied with a fine brush to recreate the special characteristics required to mimic natural teeth. $\underline{5}$ and $\underline{z}$ In contrast with the intrinsic staining technique, extrinsic staining can be worn away by toothbrushing over time because the stains are directly exposed to the oral environment. $\stackrel{7}{ }$ Anil and Bolay $\underline{8}$ showed that extrinsic stain should be placed as deeply as possible in the restoration to ensure its durability.

Toothbrushing is well known as a preventive strategy for common dental diseases ${ }^{9}$ and is the most effective way to remove plaque and consequently prevent caries. $\underline{9}, \underline{10}, \underline{11}$ and $\underline{12}$ Toothpastes contain abrasive components; therefore, dentists should prescribe the dentifrice that is the least harmful to the natural dentition. 12 Toothpaste abrasiveness is measured with relative dentin abrasivity (RDA). The American Dental Association allows for a maximum RDA of 250.13 Several studies have shown that toothbrushing can affect extrinsically stained feldspathic porcelain restorations. $\underline{5}, \underline{6}, \underline{7}, \underline{8}, \underline{12}$ and $\underline{14}$ Anil and Bolay ${ }^{8}$ reported a significant change in shade and the decreased surface roughness of extrinsically stained feldspathic porcelain restorations after an equivalent of 8.5 years of toothbrushing. Aker et al? demonstrated that the use of a normal toothbrush with a common dentifrice could wear away color corrective porcelain stains applied to the surface of feldspathic porcelain restorations in a period of 10 to 12 years unless a protective layer of glaze was applied over the stain. Conversely, Bativala et al $\underline{5}$ found that the extrinsic stain layer on feldspathic porcelain restorations was resistant to significant loss from the use of a fluoride dentifrice applied with a soft multitufted toothbrush for at least 8.5 years of simulated brushing. They also found that some of the stain layer on the

The Journal of Prosthetic Dentistry, Vol. 115, No. 4 (April 2016): pg. 489-494. DOI. This article is (C) Elsevier and permission has been granted for this version to appear in e-Publications@Marquette. Elsevier does not grant permission for this article to be further copied/distributed or hosted elsewhere without the express permission from Elsevier. 
feldspathic porcelain restorations remained for periods of up to 11.4 years, although the surface was significantly roughened.

Pressable ceramics are one of the most popular restorative systems because they are easy to fabricate, translucent, and exhibit marginal fit stability during firings, low shrinkage, less brittleness, and lower porosity compared with conventional feldspathic porcelain. $\underline{15}$ and $\underline{16}$ The pressable ceramic restorations are fabricated by a combination of the lost-wax and heat-pressing methods, providing excellent marginal fit and esthetic results. However, no studies have reported the effect of toothbrushing on extrinsically stained pressable ceramic materials.

The purpose of this in vitro study was to investigate the effect of toothbrushing on the shade and surface roughness of 2 types of extrinsically stained pressable ceramics. The null hypothesis of this study was that no change would be observed in the shade or surface roughness of 2 stained and/or glazed pressable ceramic materials after $3,6,9$, and 12 years of simulated toothbrushing when compared with baseline measurements.

\section{Material and Methods}

Two materials, leucite-based (IPS Empress Esthetic [EE]; Ivoclar Vivadent AG) and lithium disilicate-based ceramic (IPS e.max Press $[E P]$; Ivoclar Vivadent AG), were studied. Specimens were produced in wax with a metal mold in preparation for investing and pressing. For each material, 24 disk-shaped specimens, $10 \mathrm{~mm}$ (diameter) $\times 3$ $\mathrm{mm}$ (height), were fabricated according to manufacturer specifications and instructions (IPS Empress Esthetic [ETC1] and IPS e.max Press [LT, shade A1]; Ivoclar Vivadent AG) (Fig. 1). Each specimen contained a fiducial mark on the nontested side that was used for orientation. Specimens were ground from $3.00 \mathrm{~mm}$ to $2.90 \mathrm{~mm}$ with 320-grit through 420-grit silicon carbide paper (MetLab SiC; MetLab Corp) on a metallograph (Buehler Ltd) with water coolant to create space for a $100-\mu \mathrm{m}$ addition of extrinsic staining material. Final thicknesses were measured with a digital caliper (Westward; Grainger Inc).

The Journal of Prosthetic Dentistry, Vol. 115, No. 4 (April 2016): pg. 489-494. DOI. This article is (C) Elsevier and permission has been granted for this version to appear in e-Publications@Marquette. Elsevier does not grant permission for this article to be further copied/distributed or hosted elsewhere without the express permission from Elsevier. 
NOT THE PUBLISHED VERSION; this is the author's final, peer-reviewed manuscript. The published version may be accessed by following the link in the citation at the bottom of the page.

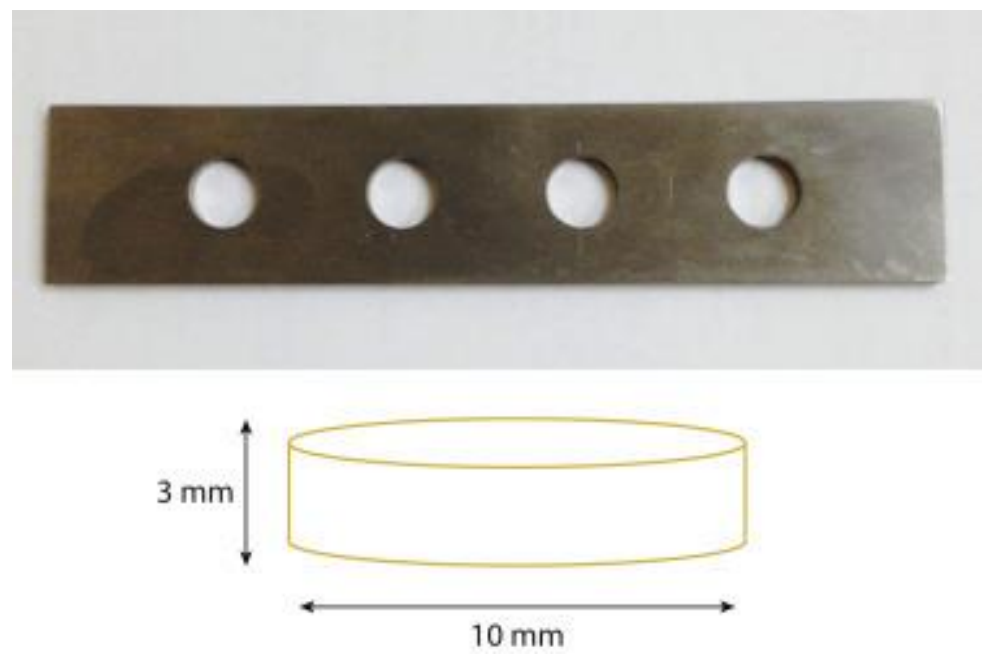

Figure 1. Mold for fabrication of disk-shaped specimens, $10 \mathrm{~mm}$ (diameter) $\times 3 \mathrm{~mm}$ (height).

Three different methods $(n=8)$ of applying extrinsic stain were used on each material: glazed only (G, control group); stained then glazed (SG); and stained and glazed together (T) (Fig. 2). Based on power analysis, a sample size of 48 achieved $80 \%$ power to detect a large effect $(f=0.45)$ with a significance level of .05 . The glazing material (IPS Empress universal glaze paste and IPS e.max Ceram glaze; Ivoclar Vivadent AG) and staining material (IPS Empress universal shade A4 and IPS e.max Ceram shade A4; Ivoclar Vivadent AG) were applied and fired for each group according to the manufacturer's instructions. After adding the stain and/or glaze materials, the specimens were measured again and ground with 320grit through 420-grit silicon carbide paper on a metallograph until a final thickness of $3 \mathrm{~mm}( \pm 30 \mu \mathrm{m})$ was achieved. This process produced specimens with a glaze and/or stain layer of $100 \mu \mathrm{m}( \pm 30$ $\mu \mathrm{m})$ thickness.

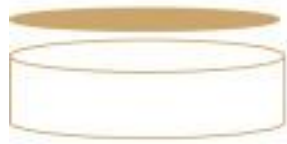

Glazed only (G, control group)

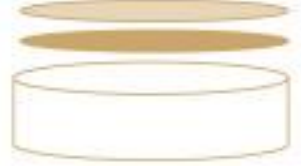

Stained then glazed (SG)

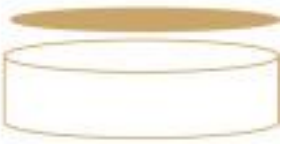

Stained and glazed together (T)

Figure 2. Stain and/or glaze application techniques.

The Journal of Prosthetic Dentistry, Vol. 115, No. 4 (April 2016): pg. 489-494. DOI. This article is @ Elsevier and permission has been granted for this version to appear in e-Publications@Marquette. Elsevier does not grant permission for this article to be further copied/distributed or hosted elsewhere without the express permission from Elsevier. 
Shade and surface roughness measurements were made at baseline and subsequently after brushing the specimens on a multistation brushing machine (Sabri Dental Enterprises Inc) (Fig. 3). The multistation brushing machine featured 4 arms and 4 reservoirs and allowed the simultaneous brushing of 8 specimens. Soft, straight toothbrushes (Oral-B \#35; Procter \& Gamble) were used in the brush heads. The reservoirs were filled with a solution made from $150 \mathrm{~g}$ of medium abrasive 70 RDA toothpaste (Colgate Total; Colgate-Palmolive Co) suspended in $150 \mathrm{~mL}$ of distilled water (1:1 ratio). The specimens were fixed in custom polymer holders so that the fiducial mark and the brush strokes were parallel to each other. Each specimen was brushed a total of 288 hours with a load of $1.96 \mathrm{~N} \underline{10}, \underline{11}, \underline{14}, \underline{17}$ and $\underline{18}$ at a brushing rate of 90 strokes per minute with interruptions at 72,144, and 216 hours. Because 48000 strokes was equivalent to 3 years of twice-daily toothbrushing for 2 minutes,,-7 the $72,144,216$, and 288 hours correspond to $3,6,9$, and 12 years of toothbrushing. Brushes and toothpaste were replaced after every 72 hours ( 3 years) of simulated brushing. The specimens were rinsed with water and dried after brushing and before all measurements.

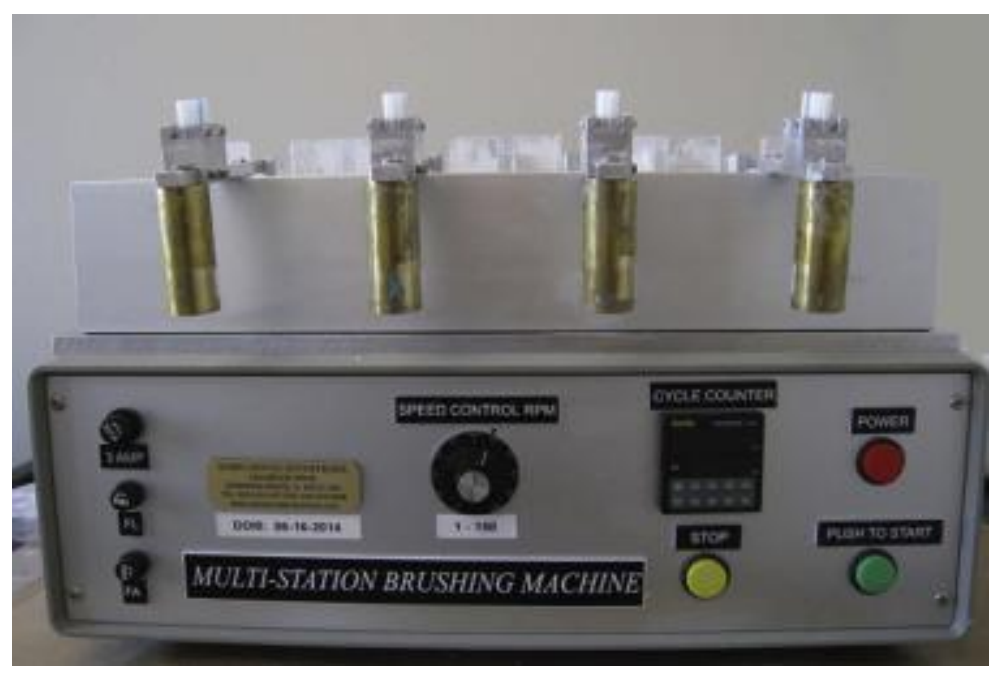

Figure 3. Multistation brushing machine.

A total of 48 specimens ( 2 materials $\times 8$ specimens $\times 3$ techniques) were evaluated for shade changes with a spectrophotometer (CM-700D; Konica Minolta) at 5 different intervals: baseline and after 72, 144, 216, and 288 hours of brushing. A spectrophotometer measures the reflected or transmitted light from a 
specific object and provides measurements corresponding to visible light wavelengths. $\underline{19}$ Before spectrophotometric analysis, the specimens were mounted in a custom mounting device to ensure repeatability of the measurement area. At each interval, measurements were made 3 times and the average used for data analysis.

Surface analysis with a contact profilometer is one method of measuring and describing the shape of a surface. The most common terminology used to describe surface contours or roughness are $R_{a}, R_{y}$, and $R_{z} . R_{a}$ is the arithmetical mean deviation of the profile average of the absolute values of the profile deviations from the mean line; $R_{y}$ is the sum of the highest peak and the deepest valley from the mean line; and $\mathrm{R}_{\mathrm{z}}$ is the average of the 5 highest peaks and the average of the 5 deepest valleys. $\underline{20}$ and $\underline{21}$ Surface roughness was evaluated with a profilometer (Mitutoyo Surftest SV-400; Mitutoyo America Corp) at baseline and after 72, 144, 216, and 288 hours of brushing. The instrument was calibrated with a standard reference specimen and then set to travel at a speed of $0.10 \mathrm{~mm} / \mathrm{s}$ with a range of $600 \mu \mathrm{m}$ during testing. A Gaussian filter and an amplitude transmittance of $50 \%$ were selected. A diamond stylus ( $5 \mu \mathrm{m}$ tip radius) was used under a constant measuring force of $3.9 \mathrm{mN}$. Surface roughness $\left(R_{a}\right)$ was measured 3 times by orienting the fiducial notch at the 11,12 , and 1 o'clock positions. The detector moved across the specimen, perpendicular to the direction of the toothbrushing movement. The surface analyzer determined a roughness profile of each specimen based on the average of the 3 measurements.

A total of 1440 measurements (48 specimens $\times 3$ shade measurements $\times 3$ roughness measurements $\times 5$ intervals) were collected by 1 examiner (L.G.). A repeated measures ANOVA was used to evaluate shade and roughness $(a=.05)$ with time as a repeated factor and technique as a fixed factor. Separate analyses were performed for each material, and a Bonferroni correction was made to control the Type I error.

The Journal of Prosthetic Dentistry, Vol. 115, No. 4 (April 2016): pg. 489-494. DOI. This article is @ Elsevier and permission has been granted for this version to appear in e-Publications@Marquette. Elsevier does not grant permission for this article to be further copied/distributed or hosted elsewhere without the express permission from Elsevier. 
NOT THE PUBLISHED VERSION; this is the author's final, peer-reviewed manuscript. The published version may be accessed by following the link in the citation at the bottom of the page.

\section{Results}

Table 1 summarizes the mean (SD) values of shade change $(\Delta \mathrm{E})$ for each subgroup during the 12 years of toothbrushing. The mean values of shade change $(\Delta \mathrm{E})$ after 12 years ranged from 0.16 to 0.66 .

Table 1. Mean (SD) of shade change values $(\Delta E)$ for each subgroup

\begin{tabular}{|c|c|c|c|c|c|c|c|}
\hline \multirow{2}{*}{$\begin{array}{l}\text { Brush Year } \\
\text { Group }\end{array}$} & \multicolumn{3}{|c|}{ Baseline (Before Brushing) } & \multicolumn{4}{|c|}{$\Delta E$ Value, Mean (SD) } \\
\hline & L* & a* & b* & $3 \mathbf{Y}$ & $6 Y$ & $9 \mathrm{Y}$ & $12 Y$ \\
\hline \multicolumn{8}{|l|}{$\mathrm{EE}$} \\
\hline G & 74.84 & 0.41 & 6.50 & $\begin{array}{l}0.14 \\
(0.07)\end{array}$ & $\begin{array}{l}0.20 \\
(0.14)\end{array}$ & $\begin{array}{l}0.16 \\
(0.08)\end{array}$ & $0.16(0.09)$ \\
\hline SG & 70.71 & 4.23 & 11.56 & $\begin{array}{l}0.29 \\
(0.28)\end{array}$ & $\begin{array}{l}0.52 \\
(0.65)\end{array}$ & $\begin{array}{l}0.22 \\
(0.17)\end{array}$ & $0.18(0.11)$ \\
\hline $\mathrm{T}$ & 66.53 & 6.56 & 20.95 & $\begin{array}{l}0.17 \\
(0.07)\end{array}$ & $\begin{array}{l}0.12 \\
(0.12)\end{array}$ & $\begin{array}{l}0.15 \\
(0.10)\end{array}$ & $0.16(0.11)$ \\
\hline \multicolumn{8}{|l|}{ EP } \\
\hline G & 72.27 & 0.68 & 8.97 & $\begin{array}{l}0.12 \\
(0.07)\end{array}$ & $\begin{array}{l}0.18 \\
(0.11)\end{array}$ & $\begin{array}{l}0.21 \\
(0.12)\end{array}$ & $0.22(0.13)$ \\
\hline SG & 55.10 & 8.66 & 19.05 & $\begin{array}{l}0.23 \\
(0.13)\end{array}$ & $\begin{array}{l}0.26 \\
(0.15)\end{array}$ & $\begin{array}{l}0.32 \\
(0.16)\end{array}$ & $0.51(0.32)$ \\
\hline $\mathrm{T}$ & 50.78 & 10.92 & 23.04 & $\begin{array}{l}0.30 \\
(0.15)\end{array}$ & $\begin{array}{l}0.35 \\
(0.13)\end{array}$ & $\begin{array}{l}0.82 \\
(0.45)\end{array}$ & $0.66(0.32)$ \\
\hline
\end{tabular}

$\Delta \mathrm{E}=$ Change in color, $\Delta \mathrm{E}=\left(\left[\mathrm{L}_{1}-\mathrm{L}_{2}\right]^{2}+\left[\mathrm{b}_{1}=\mathrm{b}_{2}\right]^{2}+\left[\mathrm{a}_{1}-\mathrm{a}_{2}\right]^{2}\right)^{1 / 2}$.

Table 2 lists the mean values and SD of roughness change $\left(\Delta R_{a}\right)$ up to 12 years for each group. The values of $\Delta R_{a}$ were calculated from the following formula: $R_{a}$ (brush year)- $R_{a}$ (baseline). Most $\Delta R_{a}$ values show a slight increase in $\Delta R_{a}$ over time, except the EE-G and EE-T groups, which displayed negative values. A negative $\Delta R_{a}$ value indicates that smoothening of the surface occurred over time.

Table 2. Mean (SD) of roughness change values $\left(\Delta R_{a}\right.$ in $\left.\mu \mathrm{m}\right)$ of each subgroup

$\begin{array}{lccccc}\begin{array}{l}\text { Brush Year Group Baseline } \\ \text { EE }\end{array} & \mathbf{3} \mathbf{Y} & \mathbf{6} \mathbf{Y} & \mathbf{9} \mathbf{Y} & \mathbf{1 2} \mathbf{Y} \\ \mathrm{G} & 0.33 & -0.06(0.09) & -0.02(0.11) & -0.04(0.15) & -0.01(0.11) \\ \mathrm{SG} & 0.14 & 0.02(0.04) & 0.03(0.04) & 0.03(0.03) & 0.04(0.04) \\ \mathrm{T} & 0.19 & -0.02(0.04) & 0.01(0.07) & 0.04(0.07) & 0.07(0.09) \\ \mathrm{EP} & & & & & \\ \mathrm{G} & 0.15 & 0.02(0.05) & 0.01(0.10) & 0.06(0.12) & 0.06(0.11) \\ \mathrm{SG} & 0.15 & 0.03(0.06) & 0.03(0.04) & 0.04(0.06) & 0.07(0.07) \\ \mathrm{T} & 0.10 & 0.06(0.05) & 0.08(0.04) & 0.10(0.05) & 0.13(0.09) \\ & & & & \end{array}$

The Journal of Prosthetic Dentistry, Vol. 115, No. 4 (April 2016): pg. 489-494. DOI. This article is @ Elsevier and permission has been granted for this version to appear in e-Publications@Marquette. Elsevier does not grant permission for this article to be further copied/distributed or hosted elsewhere without the express permission from Elsevier. 
Table 3 indicates the results of repeated measures ANOVA. Analyses were performed separately for the EE and EP groups. All assumptions, including a sphericity assumption, of the repeated measures ANOVA were satisfied. Overall for the EE group, no significant shade change or surface roughness change was noted after 12 years of simulated brushing, irrespective of time and staining technique $(P>.05)$. Conversely, the EP group revealed a significant change in shade $(P=.001)$ and roughness $(P=.001)$ as a function of brush year. The roughness change of the EP subgroups depended only on brush year. However, shade change was found to depend on brushing time and staining technique $(P=.005)$. For the EP subgroup, the 2-step technique (EP-SG) had less shade change over time compared with the EP-T subgroups $(P=.039)$.

Table 3. Repeated measures ANOVA $(a=.05)$

\begin{tabular}{|c|c|c|}
\hline \multicolumn{3}{|c|}{ Group/Source of Variance Shade $(\Delta E)$ Roughness $\left(\Delta R_{a}\right)$} \\
\hline \multicolumn{3}{|l|}{ EE } \\
\hline Brush year & .269 & .141 \\
\hline Brush year $\times$ technique & .268 & .482 \\
\hline \multicolumn{3}{|l|}{ Technique } \\
\hline $\mathrm{G}$ versus $\mathrm{SG}$ & .078 & .085 \\
\hline G versus $T$ & .965 & .319 \\
\hline SG versus $T$ & $.047 *$ & .724 \\
\hline \multicolumn{3}{|l|}{ EP } \\
\hline Brush year & $.001 *$ & $.001 *$ \\
\hline Brush year $\times$ technique & $.005 *$ & .709 \\
\hline \multicolumn{3}{|l|}{ Technique } \\
\hline G versus SG & .166 & .989 \\
\hline$G$ versus $T$ & $.001 *$ & .994 \\
\hline SG versus $T$ & $.039=$ & .989 \\
\hline
\end{tabular}

* Statistically significant $(P<.05)$.

A post hoc test for comparing $\triangle \mathrm{E}$ and $\Delta \mathrm{R}_{\mathrm{a}}$ at 3-year toothbrushing intervals in the groups EP-SG and EP-T is shown in Table 4. In terms of shade change for EP-SG, a statistically significant difference was noted between the 9-year and 12-year intervals $(P=.047)$. In the EP-T group, statistically significant shade changes were noted at baseline and 3 years $(P=.005)$ and between the 6-year and 9-year intervals $(P=.005)$. Furthermore, a statistically significant change in surface roughness $\left(\Delta R_{a}\right)$ was noted between base line and the 3-year interval for the EP-T subgroup $(P=.005)$.

The Journal of Prosthetic Dentistry, Vol. 115, No. 4 (April 2016): pg. 489-494. DOI. This article is (C) Elsevier and permission has been granted for this version to appear in e-Publications@Marquette. Elsevier does not grant permission for this article to be further copied/distributed or hosted elsewhere without the express permission from Elsevier. 
Table 4. Post hoc comparison $(a=.05)$

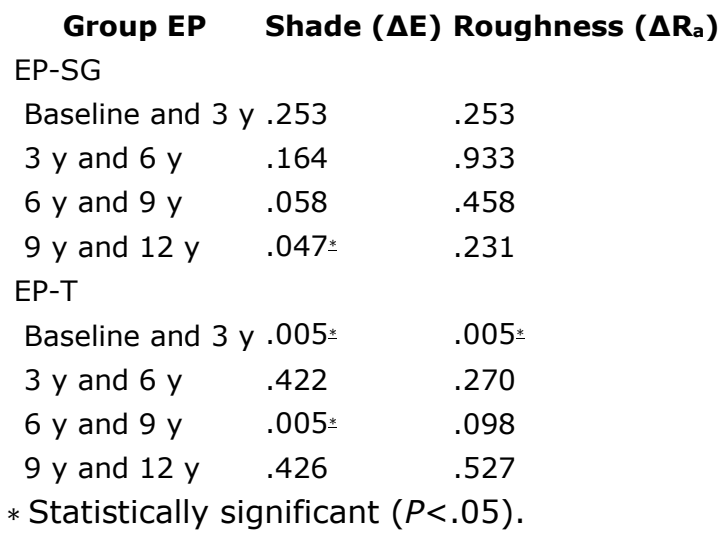

\section{Discussion}

The effect of toothbrushing on the shade and surface roughness of extrinsically stained pressable ceramics was investigated. The null hypothesis of the study was rejected for the EP group for both shade and roughness; the null hypothesis was not rejected for the EE group.

Several studies of extrinsically stained feldspathic porcelain materials have reported similar results as in the present study. Anil and Bolay 8 found a significant color change in extrinsically stained feldspathic dental porcelain after an equivalent of 8.5 years of toothbrushing. Aker et al $\mathrm{p}$ demonstrated that toothbrushing could wear the surface stain of feldspathic ceramic restorations over a period of 10 to 12 years unless a protective layer of glaze was applied. The present study demonstrated that a significant shade change occurred after an equivalent of 12 years of toothbrushing for the EP group $(P=.001)$. A significant difference was found between the EP-SG and EP-T groups $(P=.039)$. After 12 years of simulated toothbrushing, the 2-step technique (SG) was found to be more resistant to shade change than the $T$ staining technique $(T)$. This implies that the glaze layer applied over the stain layer may play a protective role. In contrast with EP, no significant difference in shade change was found for EE group. This could be explained by the different chemical composition and mechanical property of the 2 materials used: IPS Empress universal shade/glaze and IPS e.max Ceram shade/glaze. In addition, different firing temperatures could affect the stain stability 
found in the present study. However, Mulla and Weiner $\underline{22}$ demonstrated no difference between 2 different firing temperatures.

Previous studies $\underline{5}, \underline{7}$ and $\underline{8}$ used the stain application technique described by Lund et $a l, \underline{6}$ which relied on visual assessment for stain application. Assessing color with the human eye is considered inconsistent because of external variables such as light and internal variables such as age, fatigue, sex, color blindness, personal bias, and experience. $\underline{2}$ Conversely, the present study used a controlled stain and glaze application procedure that facilitated the reproducibility of manufactured specimens. Moreover, color change $(\Delta E)$ was measured with a spectrophotometer, which can provide a more consistent and objective evaluation than the human eye. $\underline{23}$

Although shade was found to be significantly affected in the EP group, it was not clinically significant. In order to understand the clinical significance of any shade changes, color tolerances, such as perceptible tolerances and acceptability tolerances, must be understood. Perceptible tolerances have been defined as the amount of color difference that might be detected visually. Acceptability tolerances have been defined as the alteration of color that is considered esthetically unacceptable. ${ }^{1}$ Douglas et al ${ }^{1}$ summarized different studies that evaluated color-matching tolerances. Most of those studies were performed in nonclinical conditions. A study that was performed in a clinical scenario reported a perfect color match to have a $\Delta \mathrm{E}$ of 3.7 ; barely acceptable matches were found to have $\Delta \mathrm{E}$ of 6.8. $\stackrel{24}{ }$ A more recent clinical study by Douglas et al 1 reported perceptibility tolerances to be at 2.6 $\Delta \mathrm{E}$, while acceptability was 5.5 $\Delta \mathrm{E}$. The present study found mean $\Delta \mathrm{E}$ values for both materials to be as low as 0.16 and as high as 0.66 after 12 years of toothbrushing. Although a statistically significant shade change $(\Delta E)$ was noted after 12 years of toothbrushing, the values of shade change $(\Delta \mathrm{E})$ were small compared with the clinical threshold for perceptibility and acceptability. This means that the shade change values found in this study would not be considered clinically significant.

In terms of surface roughness, Anil and Bolay ${ }^{8}$ found a significant decrease in the roughness of extrinsically stained feldspathic dental porcelain after an equivalent of 8.5 years of toothbrushing. In comparison, the present study found that mean $R_{a}$

The Journal of Prosthetic Dentistry, Vol. 115, No. 4 (April 2016): pg. 489-494. DOI. This article is (C) Elsevier and permission has been granted for this version to appear in e-Publications@Marquette. Elsevier does not grant permission for this article to be further copied/distributed or hosted elsewhere without the express permission from Elsevier. 
values increased slightly over time. This inconsistency may be the result of differences in testing methods. Anil and Bolay $\underline{8}$ used a different brushing machine, greater brushing load $(5.88 \mathrm{~N})$, and harder nylon toothbrushes, while the present study used a lighter brushing load (1.96 N, an average obtained from the literature $\underline{10}, \underline{11}, \underline{14}, \underline{17}$ and $\underline{18}$ ) and a soft, straight Oral-B \#35 toothbrush. $\underline{14}$ and $\underline{18}$ All of the groups in the present study became rougher, with 1 exception: the EE-G subgroup, which possessed a higher baseline roughness than the other samples, became smoother ( -0.06 at 3 years to -0.01 at 12 years).

Patients can perceive a roughened surface $\left(R_{a}\right)$ of $0.50 \mu \mathrm{m}$ clinically. $\underline{25}$ The present study determined a mean $R_{a}$ value of 0.32 (EEG), 0.18 (EE-SG), 0.26 (EE-T), 0.21 (EP-G), 0.22 (EP-SG), and 0.23 (EP-T) after 12 years toothbrushing. These numbers are below the clinical thresholds noted above. Even though the EP group demonstrated a statistically significant change in roughness as a function of brushing time and techniques $(P<.05)$, it is not considered to be clinically significant.

This study has several limitations. First, there was a variance of $\pm 30 \mu \mathrm{m}$ among the groups in regard to the thickness of the stain and/or glaze layers. However, it should be noted that $\Delta E$ and $\Delta R_{a}$ were outcome measures used for statistical comparisons and not absolute values. Second, the current American Dental Association recommendation for toothbrush replacement is every 3 to 4 months. $\underline{26}$ This frequency could change the results of the present study. However, in the present study, the slurry and toothbrushes were replaced after every 3 years of simulated toothbrushing because of experimental design and time management. If the test toothbrush bristles lost their stiffness, it could manifest as a minimal increase in surface roughness. Many types of toothpastes are commercially available for toothbrushing. Some believe that toothbrush abrasion and recession are the results of toothbrushing. However, one study proved that abrasion was due to the effect of the dentifrice only and had no relationship to the toothbrush. $\underline{12}$ The composition of the slurry used did not contain saliva or synthetic saliva and did not replicate the oral environment. Last, no real comparisons could be made with previous studies because of the difference in protocols and the use of dissimilar materials. Further studies will be needed to investigate the

The Journal of Prosthetic Dentistry, Vol. 115, No. 4 (April 2016): pg. 489-494. DOI. This article is (C) Elsevier and permission has been granted for this version to appear in e-Publications@Marquette. Elsevier does not grant permission for this article to be further copied/distributed or hosted elsewhere without the express permission from Elsevier. 
NOT THE PUBLISHED VERSION; this is the author's final, peer-reviewed manuscript. The published version may be accessed by following the link in the citation at the bottom of the page.

effect of different brushing systems, such as with electronic toothbrushes and fluoride toothpastes.

\section{Conclusions}

Within the limitations of this study, the following conclusions may be drawn:

1. No statistically significant difference was found in the shade change and surface roughness of the extrinsically stained EE groups after 12 years of simulated toothbrushing.

2. Statistically significant differences were found in the shade change and surface roughness of the extrinsically stained EP groups after 12 years of simulated toothbrushing.

\section{Acknowledgments}

The authors thank Ivoclar Vivadent for providing the materials and allowing the use of their equipment, facilities; Drs Shashikant Singhal and Thomas Hill for help with specimen fabrication; and SABRI Inc for providing the toothbrushing machine apparatus, without which, this project would not have been possible.

\section{References}

1 R.D. Douglas, T.J. Steinhauer, A.G. Wee. Intraoral determination of the tolerance of dentists for perceptibility and acceptability of shade mismatch. J Prosthet Dent, 97 (2007), pp. 200-208

2 N. AlGhazali, G. Burnside, R.W. Smith, A.J. Preston, F.D. Jarad. Performance assessment of Vita Easy Shade spectrophotometer on colour measurement of aesthetic dental materials. Eur J Prosthodont Restor Dent, 19 (2011), pp. 168-174

3 A. Dozić, C.J. Kleverlaan, A. El-Zohairy, A.J. Feilzer, G. Khashayar. Performance of five commercially available tooth color-measuring devices. J Prosthodont, 16 (2007), pp. 93-100

4 S. Schultheis, J.R. Strub, T.A. Gerds, P.C. Guess. Monolithic and bi-layer CAD/CAM lithium-disilicate versus metal-ceramic fixed dental prostheses: comparison of fracture loads and failure modes after fatigue. Clin Oral Investig, 17 (2013), pp. 1407-1413

5 F. Bativala, S. Weiner, P. Berendsen, G.R. Vincent, J. Ianzano, W.T. Harris. The microscopic appearance and effect of toothbrushing on

The Journal of Prosthetic Dentistry, Vol. 115, No. 4 (April 2016): pg. 489-494. DOI. This article is @ Elsevier and permission has been granted for this version to appear in e-Publications@Marquette. Elsevier does not grant permission for this article to be further copied/distributed or hosted elsewhere without the express permission from Elsevier. 
extrinsically stained metal-ceramic restorations. J Prosthet Dent, 571 (1987), pp. 47-52

6 T.W. Lund, W.B. Schwabacher, R.J. Goodkind. Spectrophotometric study of the relationship between body porcelain color and applied metallic oxide pigments. J Prosthet Dent, 53 (1985), pp. 790-796

7 D.A. Aker, J.R. Aker, S.E. Sorensen. Toothbrush abrasion of color-corrective porcelain stains applied to porcelain-fused-to-metal restorations. J Prosthet Dent, 44 (1980), pp. 161-163

8 N. Anil, S. Bolay. Effect of toothbrushing on the material loss, roughness, and color of intrinsically and extrinsically stained porcelain used in metal-ceramic restorations: an in vitro study. Int J Prosthodont, 15 (2002), pp. 483-487

9 T. Arai, S. Kinoshita. A comparison of plaque removal by different toothbrushes and toothbrushing methods. Bull Tokyo Med Dent Univ, 24 (1977), pp. 177-188

10 G.I. McCracken, J. Janssen, M. Swan, N. Steen, M. de Jager, P.A. Heasman. Effect of brushing force and time on plaque removal using a powered toothbrush. J Clin Periodontol, 30 (2003), pp. 409-413

11 G.A. Van der Weijden, M.F. Timmerman, M.M. Danser, U. Van der Velden. Relationship between the plaque removal efficacy of a manual toothbrush and brushing force. J Clin Periodontol, 25 (1998), pp. 413416

12 S. Kinoshita, T. Arai, R. Uraguchi. Abrasive properties of commonly used dentifrices. Bull Tokyo Med Dent Univ, 26 (1979), pp. 225-242

13 J. da Costa, A. Adams-Belusko, K. Riley, J.L. Ferracane. The effect of various dentifrices on surface roughness and gloss of resin composites. J Dent, 38 (suppl 2) (2010), pp. e123-e128

14 J.C. Wataha, P.E. Lockwood, R.L. Messer, J.B. Lewis, D.J. Mettenburg. Brushing-induced surface roughness of nickel-, palladium-, and goldbased dental casting alloys. J Prosthet Dent, 99 (2008), pp. 455-460

15 S.H. Cho, W.W. Nagy, J.T. Goodman, E. Solomon, M. Koike. The effect of multiple firings on the marginal integrity of pressable ceramic single crowns. J Prosthet Dent, 107 (2012), pp. 17-23

16 H.J. Conrad, W.J. Seoung, I.J. Pesun. Current ceramic materials and systems with clinical recommendations: a systematic review. J Prosthet Dent, 98 (2007), pp. 389-404

17 A. Wiegand, J.P. Burkhard, F. Eggmann, T. Attin. Brushing force of manual and sonic toothbrushes affects dental hard tissue abrasion. Clin Oral Investig, 17 (2013), pp. 815-822

18 J.C. Wataha, P.E. Lockwood, M. Noda, S.K. Nelson, D.J. Mettenburg. Effect of toothbrushing on the toxicity of casting alloys. J Prosthet Dent, 87 (2002), pp. 94-98

The Journal of Prosthetic Dentistry, Vol. 115, No. 4 (April 2016): pg. 489-494. DOI. This article is @ Elsevier and permission has been granted for this version to appear in e-Publications@Marquette. Elsevier does not grant permission for this article to be further copied/distributed or hosted elsewhere without the express permission from Elsevier. 
19 J.D. Da Silva, S.E. Park, H.P. Weber, S. Ishikawa-Nagai. Clinical performance of a newly developed spectrophotometric system on tooth color reproduction. J Prosthet Dent, 99 (2008), pp. 361-368

20 S.A. Whitehead, A.C. Shearer, D.C. Watts, N.H. Wilson. Comparison of two stylus methods for measuring surface texture. Dent Mater, 15 (1999), pp. 79-86

21 C.Y. Poon, B. Bhushan. Comparison of surface roughness measurements by stylus profiler, AFM and non-contact optical profiler. Wear, 190 (1995), pp. 76-88

$\underline{22}$ F.A. Mulla, S. Weiner. Effects of temperature on color stability of porcelain stains. J Prosthet Dent, 65 (1991), pp. 507-512

23 S. Paul, A. Peter, N. Pietrobon, C.H. Hämmerle. Visual and spectrophotometric shade analysis of human teeth. J Dent Res, 81 (2002), pp. 578-582

24 W.M. Johnston, E.C. Kao. Assessment of appearance match by visual observation and clinical colorimetry. J Dent Res, 68 (1989), pp. 819822

25 C.S. Jones, R.W. Billington, G.J. Pearson. The in vivo perception of roughness of restorations. Br Dent J, 196 (2004), pp. 42-45

26 P.M. Glaze, A.B. Wade. Toothbrush age and wear as it relates to plaque control. J Clin Periodontol, 13 (1986), pp. 52-56

Supported by an American Academy of Fixed Prosthodontics Stanley D. Tylman Research Grant and the Marquette University School of Dentistry Student Research Fund.

Corresponding author: Dr Seok-Hwan Cho, Marquette University School of Dentistry, 1801 W Wisconsin Ave, Milwaukee, WI 53233 